\title{
Pioneer shunt implantation surgery in Brazil
}

\author{
Roberto Alexandre Dezena ${ }^{1}$, Jaime Olavo Marquez ${ }^{1}$, João Pedro de Oliveira Jr. ${ }^{1}$, Fernando \\ Henrique dos Reis Sousa ${ }^{1}$, Thiago Silva Paresoto ${ }^{1}$, Ana Maria Mendes Ferreira ${ }^{2}$, Pedro Henrique \\ Simm Pires de Aguiar ${ }^{3}$
}

${ }^{1}$ Division of Neurosurgery - Federal
University of Triângulo Mineiro -
Uberaba, Minas Gerais, Brazil
${ }^{2}$ Federal University of Triângulo
Mineiro - Uberaba, Minas Gerais, Brazil
${ }^{3}$ Pontifical Catholic University of São
Paulo-Sorocaba, São Paulo, Brazil
To whom correspondence
should be addressed: Roberto
Alexandre Dezena, MD, PhD
e-mail:
rdezena@yahoo.com.br
Available at:
http://www.archpedneurosurg.com.br/

Description of one of the first shunt implantation surgery in Brazil, in 1966, at Triângulo Mineiro Medical School, Uberaba

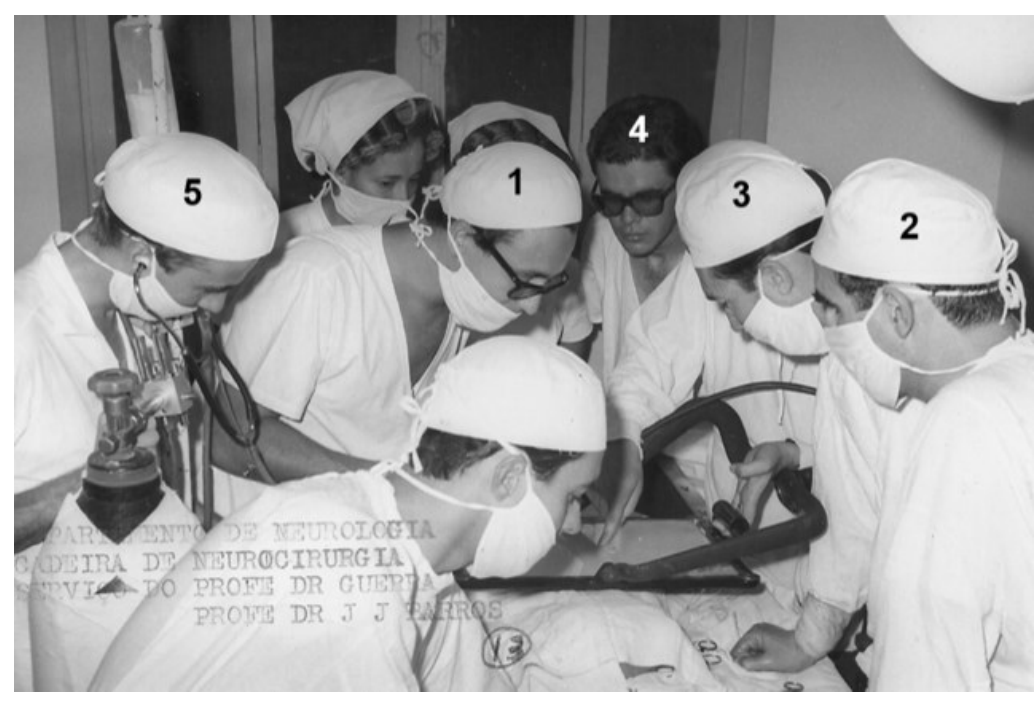

Surgical team composed by Prof. Francisco Mauro Guerra Terra (1), medical students Jaime Olavo Marquez (2), Antônio Luiz da Costa Sobrinho (3), Carlos Antunes de Paula (4), an anesthesiologist Dr. Newton Camargo Araújo (5).

Keyworks: Shun, History, Hydrocephalus

One of the first experiences of shunt implantation in the world occurred in 1949, by Nulsen and Spitz, who implanted a rubber catheter with a ball valve system, from the lateral ventricle to the internal jugular vein [1]. In the 1950s, the shunt systems had great development, especially the Spitz-Holter system, first used in 1956, consisting of the first system produced on a large scale.

The second patient who benefited from this new system was Holter's son Casey, who had myelomeningocele $[2,3]$. From these first American reports, the shunt surgery had great worldwide dissemination in the 1960s. One of the first CSF shunts in Brazil and Latin America occurred in 1966, in the city of Uberaba, Minas Gerais, by Prof. Francisco Mauro Guerra Terra, founder of the Chair of Neurosurgery at
Triângulo Mineiro Medical School, today part of Federal University of Triângulo Mineiro (UFTM).

The procedure was performed at the Children's Hospital of Uberaba, at the time one of University Hospitals, and the patient was a 7-month-old baby named Maria Beatriz. The child suffered from hydrocephalus, as a complication of tuberculous meningitis, and was diagnosed by pneumoventriculography, a procedure described by Dandy, and widely used in the era before tomography [4] (Fig. 1).

The child was submitted to a ventriculo-atrial shunt (Figs. 2, 3 and 4), with implantation of a catheter without a valve, an option widely used at the time. Besides Prof. Guerra, the surgical team was composed by the then medical 


\section{Pioneer shunt implantation surgery in Brazil}

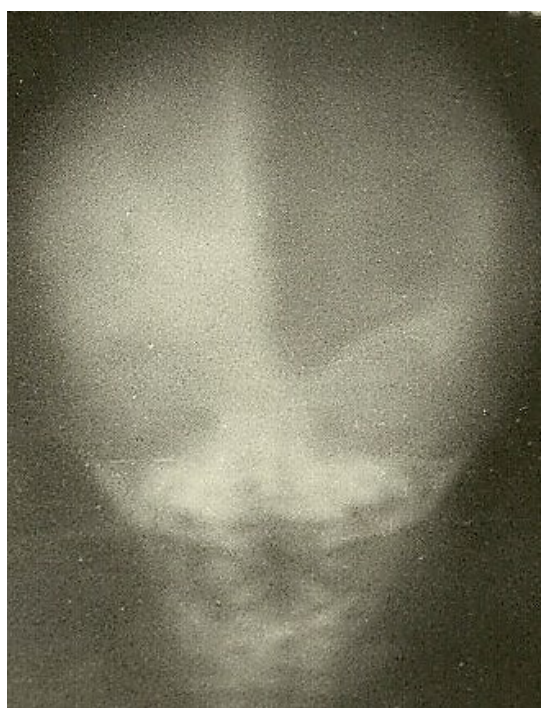

Figure 1 - Preoperative pneumoventriculography.

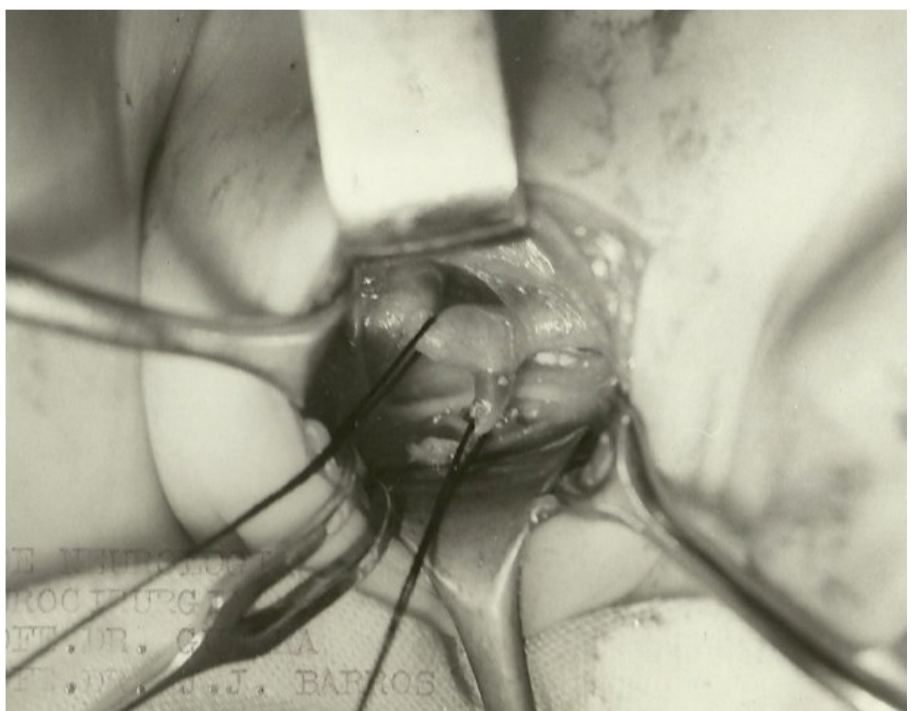

Figure 3 - Dissection of the internal jugular and facial veins for passage of the catheter.

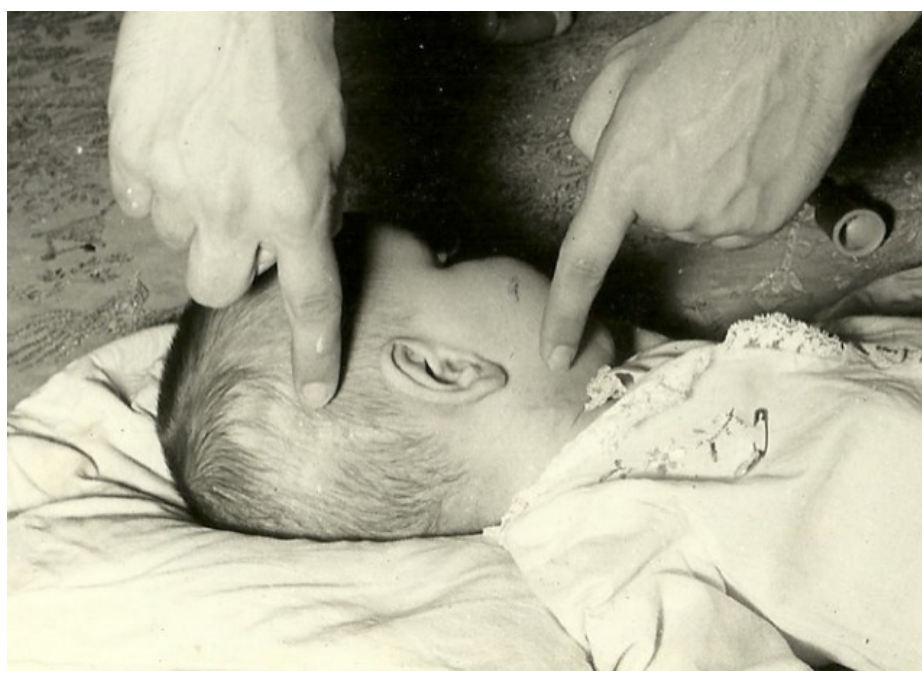

Figure 2 - Surgical planning

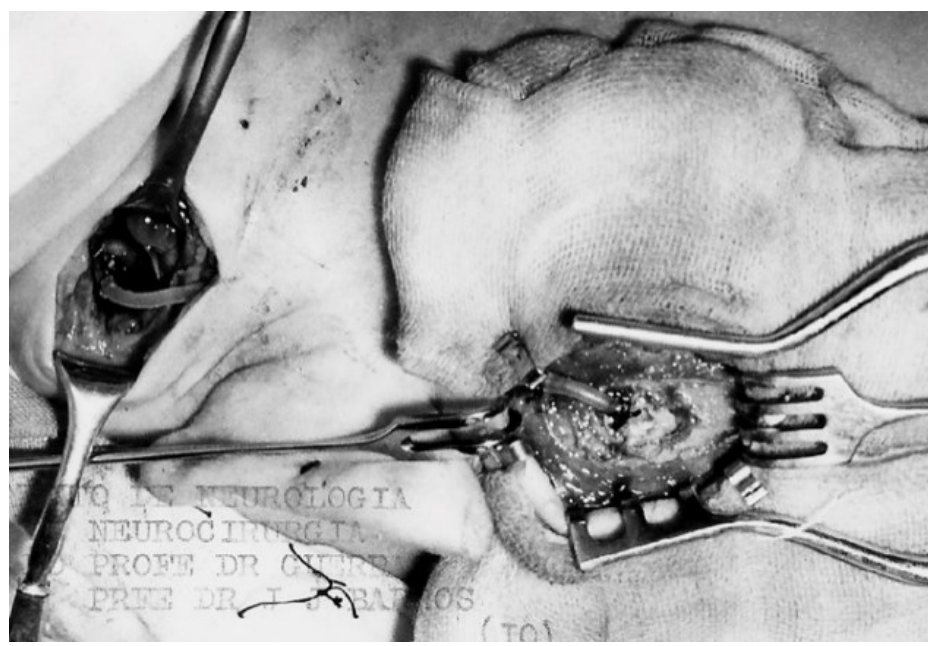

Figure 4- Exposure of the skull and cervical region, with the distal catheter alread passed.

\section{REFERENCES}

1. Nulsen FE, Spitz EB (1952) Treatment of hydrocephalus by direct shunt from ventricle to jugular vein. Surg Forum 2:399-403

2. Keen J. Casey Holter and the Spitz-Holter valve. Eur J Pediatr Surg 2 (Suppl 1):5-6, 1992

3. Symss, N.P., Oi, S. Is there an ideal shunt? A panoramic view of 110 years in CSF diversions and shunt systems used for the treatment of hydrocephalus: from historical events to current trends. Childs Nerv Syst 31, $6)$. 
191-202 (2015). https://doi.org/10.1007/s00381-0142608-z

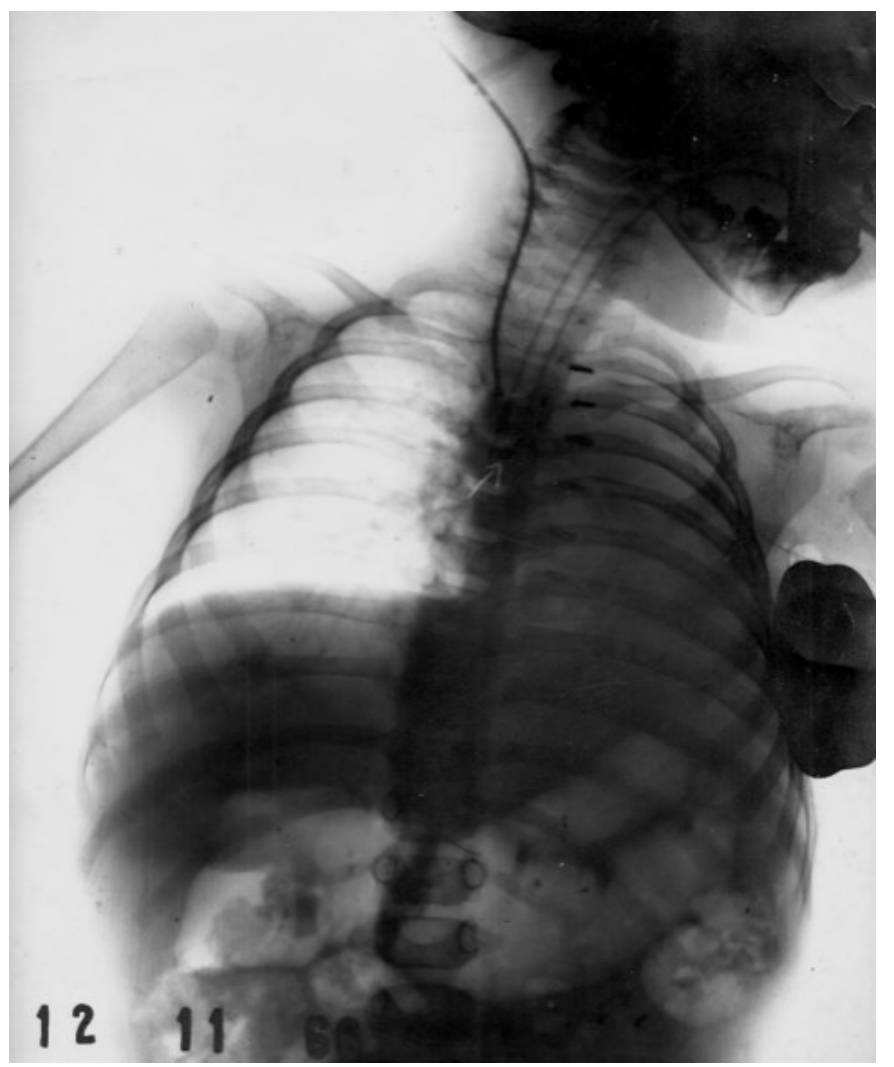

Figure 5 - Postoperative chest X-ray, with positioning of the distal catheter at the entrance to the right atrium.
4. Dandy WE. Ventriculography following the injection of air into the cerebral ventricles. Ann Surg 1918; 68: 511.

\section{olução ideal}

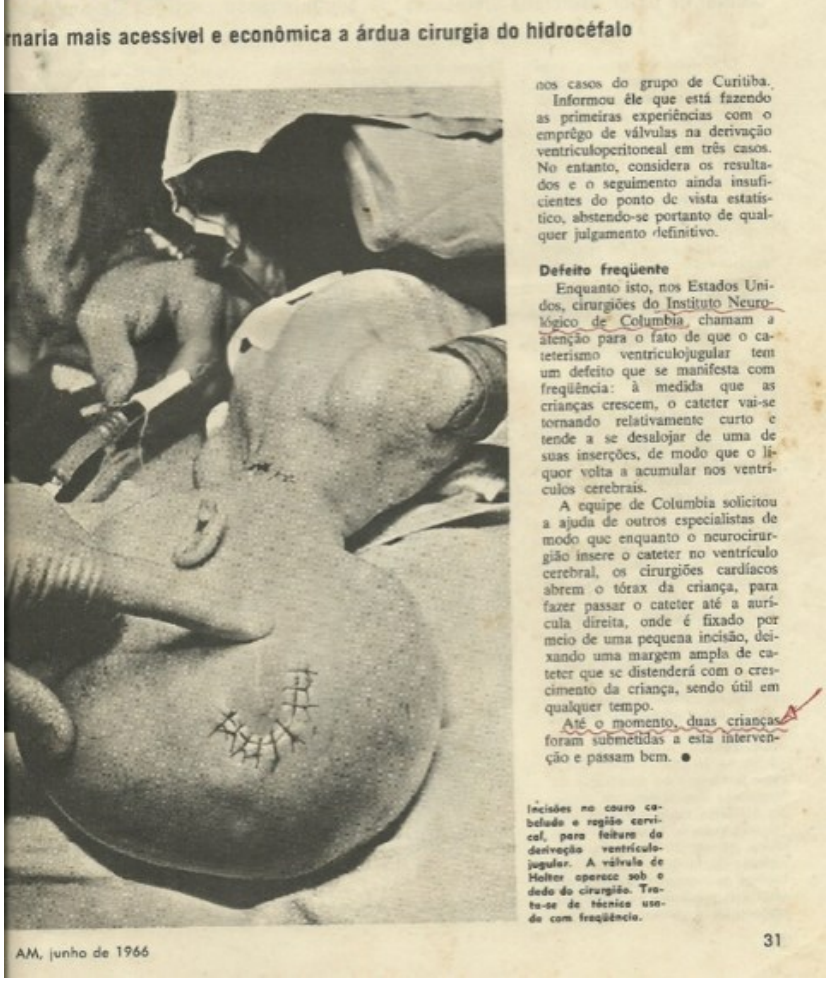

Figura 6 - Disclosure of the surgery in the printed media of the time. 